\title{
Within-ring movement of free water in dehydrating Norway spruce sapwood visualized by neutron radiography
}

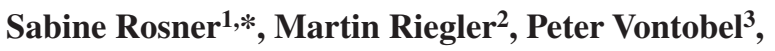 \\ David Mannes ${ }^{3}$, Eberhard H. Lehmann ${ }^{3}$, Bo Karlsson ${ }^{4}$ \\ and Christian Hansmann ${ }^{2}$ \\ ${ }^{1}$ Institute of Botany, Department of Integrative Biology, \\ University of Natural Resources and Applied Life \\ Sciences, BOKU Vienna, Gregor Mendel-Str. 33, A-1180 \\ Vienna, Austria \\ ${ }^{2}$ Competence Centre for Wood Composites and Wood \\ Chemistry, Altenberger Strasse 69, A-4040 Linz, Austria \\ ${ }^{3}$ Spallation Neutron Source, PSI, CH-5232 Villigen PSI, \\ Switzerland \\ ${ }^{4}$ The Forestry Research Institute of Sweden (Skogforsk), \\ Ekebo, S-26890 Svalöv, Sweden \\ * Corresponding author. \\ Institute of Botany, Department of Integrative Biology, \\ University of Natural Resources and Applied Life Sciences, \\ Vienna (BOKU), Gregor Mendel Str. 33, A-1180 Vienna, Austria \\ Phone: +431476543177 \\ Fax: +43 1476543180 \\ E-mail: sabine.rosner@boku.ac.at
}

\begin{abstract}
This study is a first approach to visualize moisture distribution and movement between annual rings during sapwood drying by neutron imaging (NI). While Norway spruce [Picea abies (L.) Karst.] sapwood beams were allowed to dehydrate on a balance at ambient conditions, NI was performed in 1-10 min time steps. From NI raw files, radial dimensional changes were calculated during dehydration and transmission profiles were drawn for different relative moisture content (MC) steps from full saturation until equilibrium moisture content. The NI technique proved to be a useful tool to visualize the movement of free water within, and between, annual rings. Removal of free water in the middle part of the wood beam did not proceed continuously from the surface to the central part, but was strongly influenced by wood anatomy. Water is removed from earlywood during early stages of dehydration and later, at higher moisture loss $(<50 \% \mathrm{MC})$, from the main latewood parts. It is therefore concluded that the radial dimensional changes measured at moderate moisture loss are not only caused by cell wall shrinkage of the outer wood parts located beneath the wood surface, but a result of elastic deformation of earlywood tracheids under the influence of negative hydrostatic pressures.
\end{abstract}

Keywords: image analysis; moisture movement; neutron radiography; Norway spruce; wood drying; wood shrinkage.

\section{Introduction}

Fresh, never-dried Norway spruce sapwood shows radial dimensional changes owing to dehydration stress at bulk moisture contents (MC) well above fiber saturation (Rosner et al. 2010; Hansmann et al. 2011). These dimensional changes cannot solely be explained by cell wall shrinkage of the drier outer wood layer (shell), which remains quite thin during the early stages of drying (Tremblay et al. 2000; Rosenkilde and Glover 2002; Rosenkilde et al. 2004; Salin 2007). Cell wall shrinkage is initiated when a wood conduit reaches the species specific MC of fiber saturation. This point is reached when cell lumina no longer no longer free water, but the cell walls are still fully saturated with liquid, referred to as "cell wall water" or "bound water" (Skaar 1988; Simpson and TenWolde 1999). Reversible radial dimensional changes of sapwood (SW) above fiber saturation can be observed as diurnal stem diameter changes in living Norway spruce (Offenthaler et al. 2001; Perämäki et al. 2001). Partial reversible radial dimensional changes of dehydrating conifer SW specimens (Rosner et al. 2010; Hansmann et al. 2011) are probably caused by the same effect as observed in living trees by the capillary action of free water. The economical relevance of this process is high: capillary action of free water can even lead to internal checking in living stems (Grabner et al. 2006) and to cell wall collapse or drying checks during lumber drying (Booker 1994a,b; Innes 1995; Putoczki et al. 2007; Blakemore and Langrish 2008). The partial recovery of dimensional changes well above fiber saturation is induced by a stress release when it comes to the breakage of the capillary water columns inside the conduits (Rosner et al. 2010; Hansmann et al. 2011) and not by swelling processes because cell wall rewetting of the outer wood parts by water movement from the interior parts has not been observed so far (Tarmian et al. 2009). Waveform characteristics of ultrasonic signals emitted during dehydration was interpreted as meaning that SW does not dry continuously from the shell to the core (Rosner et al. 2009). The bulk of acoustic emission in the high frequency range $(>15 \mathrm{kHz}$ ) during dehydration of wood is owing to water movement and the breakage of the water columns inside the tracheids (Kawamoto and Williams 2002). The energy of these signals increases with increasing lumen size of the tracheid (Mayr and Rosner 2011). High energy acoustic signals are emitted at moderate moisture loss (Rosner et al. 2009). Flow experiments (Rosner et al. 2006) give strong evidence that free water is removed from the highly conductive, less dense SW parts during an early stage of dehydration. Nevertheless, there is no visual proof for this hypothesis.

Neutron imaging (NI) is a relatively new, non-destructive testing method that offers the possibility of looking "inside" 
a wood specimen. Neutrons are more sensitive than X-ray beams to some major elements, such as hydrogen, and they are particularly suitable for investigating dry wood, as well as free or bound water in wood (Lehmann et al. 2001a; Mannes et al. 2007; Sonderegger et al. 2010). An oven-dry wood specimen contains ca. $6 \%$ hydrogen, which accounts for $90 \%$ of the NI attenuation, while carbon and oxygen for the rest (Mannes et al. 2009a). NI is therefore proper to investigate the wood structure together with moisture distribution (MD) within a specimen (Niemz et al. 2002; Mannes et al. 2009b; Sonderegger et al. 2010). NI is an extremely fast scanning method and allows the production of high resolution raw images within a quite big field of view.

Nuclear magnetic resonance imaging (NMRI) also allows a clear discrimination between free and bound water (Araujo et al. 1994; Almeida et al. 2007; Cox et al. 2010). For an experimental setup, where the MD remains in a state of equilibrium during the scanning time and for a smaller field of view, NMR is a good choice (Rosenkilde and Glover 2002; Rosenkilde et al. 2004; Dvinskikh et al. 2011). However, besides the combined visualization of MC, radial dimensional changes and structural features, the NI technique offers also the possibility of using electronic equipment with ferromagnetic components, such as a balance, to thus observe the bulk water loss of the specimen during the whole dehydration experiment.

The aim of the present study was to check, by means of NI, the hypothesis that free water is removed first from the sapwood regions with low density and wide lumen tracheids. More precisely, the working hypothesis was that the observed dimensional changes during dehydration above fibre saturation (Rosner et al. 2010; Hansmann et al. 2011) are not only caused by shrinking of the outer shell of the drying wood, but are also influenced by the negative pressure of free water inside the conduits and that no continuous rewetting of the outer surface layers takes place during dehydration. Neutron images were taken every minute during the first $8 \mathrm{~h}$ and thereafter every $10 \mathrm{~min}$, while the SW sample was allowed to dehydrate for $22 \mathrm{~h}$ on a balance.

\section{Material and methods}

\section{Specimen preparation}

Sapwood (SW) specimens were obtained from healthy, dominating 30-45-year-old Norway spruce [Picea abies (L.) Karst.] harvested in Prinzersdorf (Lower Austria) and in Ekebo (Southern Sweden). Wood bole segments, $200 \mathrm{~mm}$ in length, were taken immediately after felling at breast height and were kept wet in plastic bags containing some fresh water. Outer SW specimens with a transverse surface of about $9 \times 9 \mathrm{~mm}^{2}$ were isolated by splitting the wood along the grain with a chisel. The tangential and radial faces of the SW beams were planed on a sliding microtome. Specimens were shortened on a band saw and sample ends were re-cut using a razor blade. During preparation, the specimens were kept wet before they were soaked in distilled water under vacuum for $24 \mathrm{~h}$ to refill embolized tracheids (Hietz et al. 2008) and afterwards stored at $4{ }^{\circ} \mathrm{C}$ in distilled water containing $0.01 \%$ (by vol.) Micropur (Katadyn Products Inc., Wallisellen, Switzerland) to prevent microbial growth during transport. The final specimen dimensions were: $5.5 \mathrm{~mm}$ tang., $5.5 \mathrm{~mm}$ rad. and $100 \mathrm{~mm}$ long. The Prinzersdorf specimen set (tree age 45 years) contained five complete annual rings and the Ekebo set originating from a fast growing 30 -year-old tree comprised one complete annual ring.

\section{Experimental setup}

Neutron imaging was performed at the NI facility, NEUTRA, at the Paul Scherrer Institute (PSI) in Villigen, Switzerland. The imaging beam-line is fed by the Spallation Neutron Source SINQ with neutrons in a thermal spectrum (Lehmann et al. 2001b). The theoretical background, limitations of the method and the measurement device are described in detail elsewhere (Lehmann et al. 2001a, 2004; Mannes et al. 2009a,b).

Fully saturated Norway spruce SW specimens were weighed and thereafter quickly fixed on a tack, which was non-permanently glued on a sample holder (Figure 1). The tack and the sample holder were mounted with Terostat II (Henkel AG \& Co. KGaA, Düsseldorf, Germany) on the sample holder and on the balance (resolution $10^{-3} \mathrm{~g}$; Sartorius, Göttingen, Germany), respectively. The radially-cut face of the SW specimen was oriented perpendicular to the neutron beam. The distance between the specimen and the detector was $5 \mathrm{~mm}$. Specimens were dehydrated for $22 \mathrm{~h}$ at ambient conditions $\left(24-26^{\circ} \mathrm{C}, 45-50 \%\right.$ relative humidity). During the whole dehydration run, NI and bulk moisture loss were assessed automatically every minute during the first $8 \mathrm{~h}$, thereafter, every 10 $\mathrm{min}$. The detector was a scintillator-charge-coupled-device (CCD)camera system with a field-of-view of $50 \mathrm{~mm} \times 50 \mathrm{~mm}$ allowing for a spatial resolution of $51.6 \mu \mathrm{m}$ per pixel. The scintillator was a $50-\mu \mathrm{m}$ thick ${ }^{6} \mathrm{LiF}: \mathrm{ZnS}$-scintillator. The exposure time for every image was $60 \mathrm{~s}$. The samples were positioned such that their middle part was in the middle of the field-of-view (Figure 1). After the NI measurements, specimens were dried to a constant weight at $103^{\circ} \mathrm{C}$ to calculate the MC at different dehydration steps.

\section{Transmission and radial dimensional changes}

Before evaluation, raw image data were processed with ImageJ (freely available from http://rsbweb.nih.gov) in order to correct inhomogeneities of the experimental setup. As a first step, raw images with lower values in the open beam region than the average open beam level were selected by visual examination and

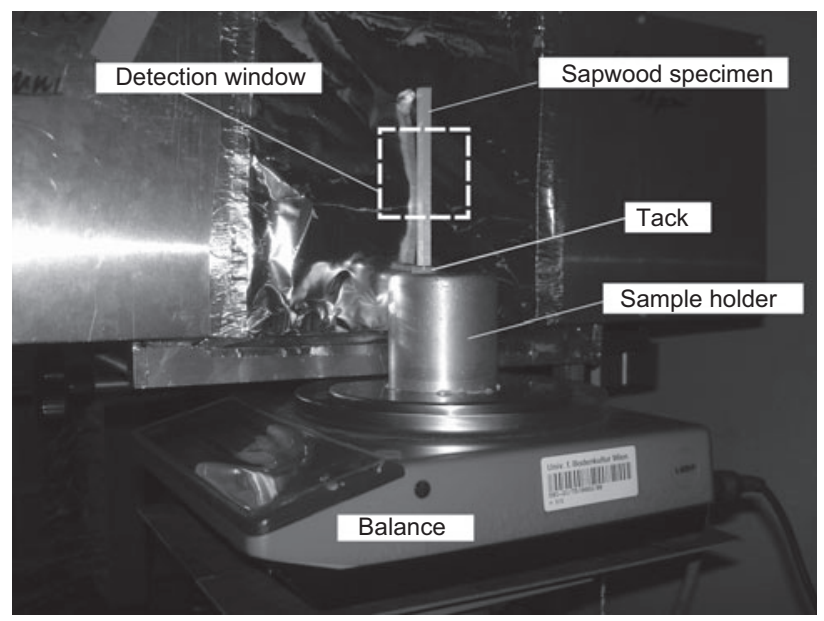

Figure 1 Experimental setup. 
were excluded from analysis. Such black or under-exposed images can result from fluctuations in the neutron production which lead to data gaps between the defined measuring intervals. Keeping in mind the long duration of the experiment, a data loss of $<10 \%$ was quite acceptable.

After sorting, the images were processed: a median filter (despeckle function) was used to eliminate outliers such as "white-spots". The offset caused by the background noise of the CCD camera was subtracted and the images were flat-field corrected to reduce the impact of the inhomogeneities of the neutron beam and the scintillator. The standard transformations described here are common to all transmission based methods (Mannes et al. 2009a).

Transmission plot profiles from the middle part of the SW specimen were processed for 12 moisture loss steps. The specimen shrinks up to $5 \%$ upon dehydration in the radial direction (Rosner et al. 2010); therefore, it was impossible to produce a plot of transmission against time of a small defined location within the specimen, particularly of the outer parts.

Images used for the transmission plot profiles were brightness-/ contrast-adjusted so that in the 32-bit files the minimum displayed value was " 0 " and that the maximum value displayed was " 1 ". This transformation permits a clearer visualization of the MD within the specimen. Regions with lower transmission values than in the image of the dry specimen represent areas with higher amounts of water (Lehmann et al. 2001a; Mannes et al. 2009b). The procedure "lookup tables" was then applied to the 8-bit files in order to transform dark gray areas into shades of blue (Figures $2 \mathrm{a}$ and $3 \mathrm{a}$ ). This procedure was used for visualization only; transmission plots provide a more detailed data view (Figures $4 \mathrm{~b}$ and $5 \mathrm{~b}$ ).

The radial dimensional changes were calculated with MATLAB, where the 8-bit grayscale transmission plot profiles were pretreated with a threshold of $245(0=$ black, $255=$ white $)$ to detect the specimen edges. Additionally, measurement artifacts outside of the specimens were removed by filtering all areas smaller than 1000 pixels. To be able to cope with the blurred edges of the specimens, 30 pixel rows were taken from the middle of the samples and an arithmetic mean was calculated. For a better illustration of the radial shrinkage curve, a moving average with a subset of nine transmission plot profiles was used.

\section{Transverse sections of wood beams}

Transverse sections of the test samples were made in the regions where the transmission plots were produced. Wood cubes were re-soaked in a mixture of distilled water, ethanol and glycerin (1:1:1). Transverse sections with a thickness of $20 \mu \mathrm{m}$ were prepared on a sliding microtome. Sections were stained with methylene blue, mounted in Euparal (Merck, Darmstadt, Germany) and photographed by means of a Leica DM4000M microscope equipped with a digital camera (Leica Microsystems Wetzlar GmbH, Germany).

\section{Results and discussion}

\section{Radial dimensional changes of sapwood during dehydration}

When assessing radial dimensional changes by NI, methodical problems obscuring the contrast between specimen and background have to be taken into account. Transmission is influenced by the specimen thickness (Mannes et al. 2007). Wood also shrinks in the tangential direction - this shrinkage
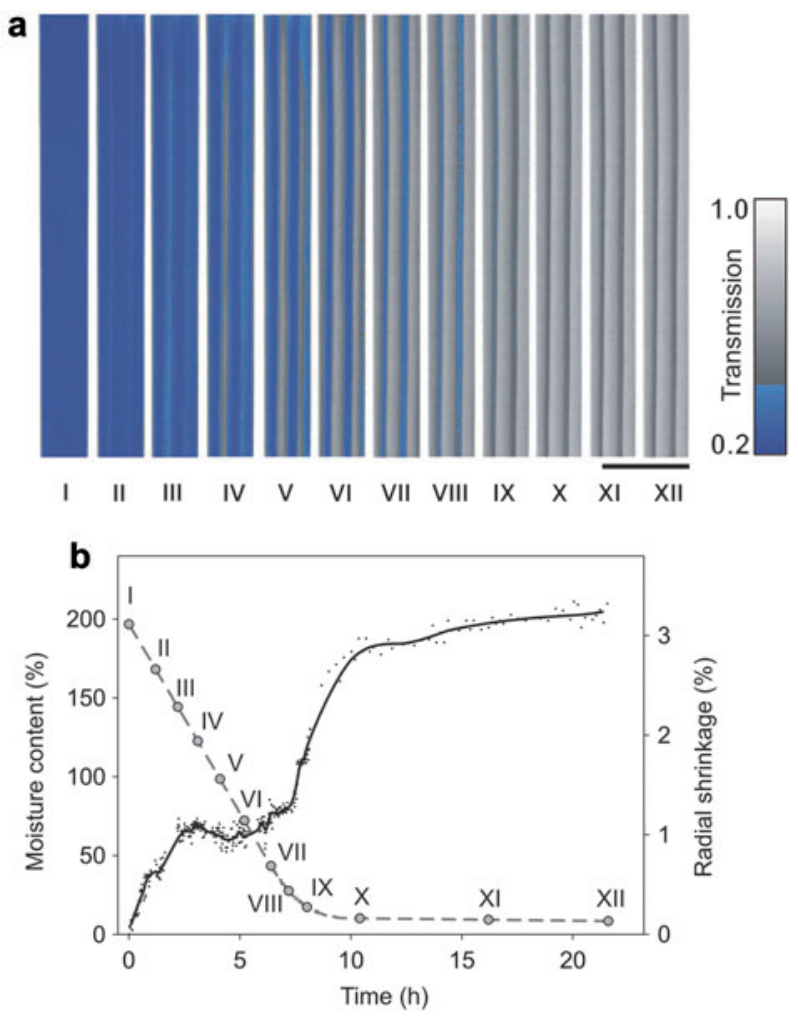

Figure 2 Neutron radiographies (a) of a sapwood beam with wide annual rings (Ekebo) at different moisture content steps (b). Moisture content (dashed line) was assessed every minute and radial shrinkage (b) was calculated as the moving average from a subset of nine transmission plot profiles. Radiographies show $5 \mathrm{~cm}$ from the middle part of the wood beam. The reference bar represents $10 \mathrm{~mm}$.

is inhomogeneous (Skaar 1988; Moon et al. 2010). Scattered neutrons can be seen as "star shine" around the object, which increases with decreasing distance to the detector (Lehmann et al. 2004) and the limited spatial resolution causes a slight blurriness at the edges (Mannes et al. 2009b). For these reasons, radial shrinkage curves obtained by image analysis of NI are not as smooth as those assessed by video extensiometry (Hansmann et al. 2011) or load cells (Rosner et al. 2009).

In both specimens, radial shrinkage started right from the beginning of dehydration (Figures $2 b$ and $3 b$ ). In the specimen with wide annual rings, radial dimensional changes ceased at $150 \% \mathrm{MC}$ and even showed a reversed trend until MC approached fiber saturation (Figure 2b). This reversible trend indicates that a high amount of the dimensional change at moderate moisture loss was induced by negative water pressure inside the cell lumina and capillaries acting perpendicular to the cell walls and trying to draw the walls inwards (Rosner et al. 2009; Hansmann et al. 2011). When the negative pressure becomes too high, the water column will break, leading to a sudden stress release which causes a relaxation of the cell walls (Tyree and Zimmermann 2002). In the specimen with narrow annual rings, this process was less pronounced (Figure $3 \mathrm{~b}$ ) because tracheids with smaller diameters are less prone to deformation caused by negative 

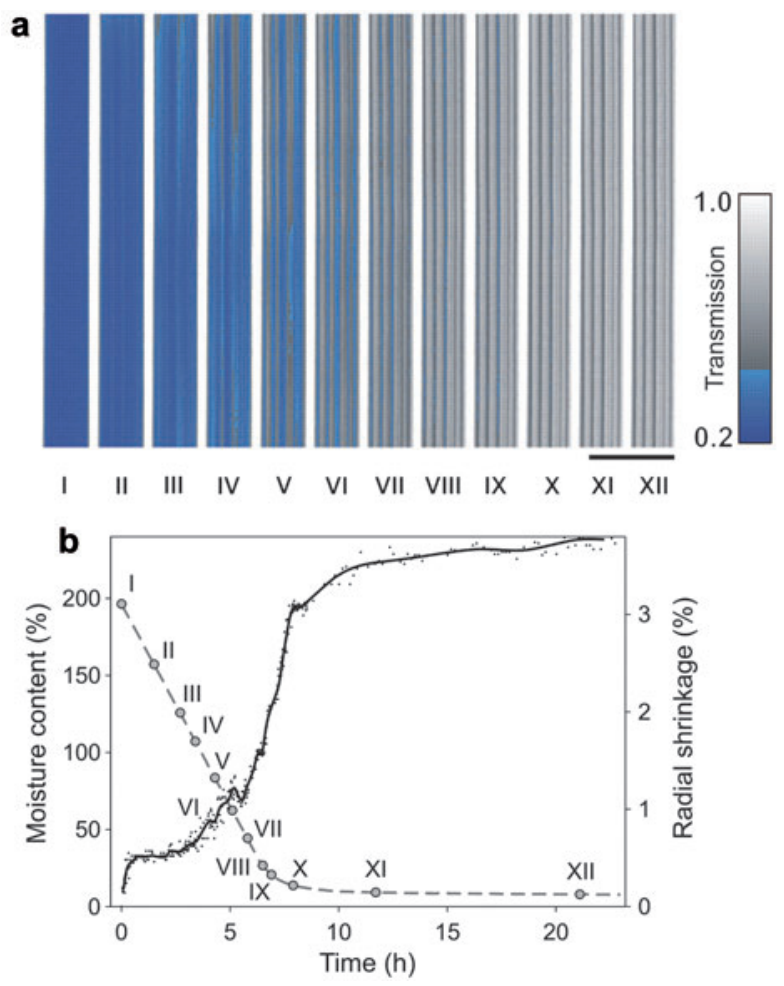

Figure 3 Neutron radiographies (a) of a dehydrating Norway spruce sapwood beam with narrow annual rings (Prinzersdorf) at different moisture content steps (b). Moisture content (dashed line) was assessed every minute and radial shrinkage (b) was calculated as the moving average from a subset of nine transmission plot profiles. Radiographies show $5 \mathrm{~cm}$ from the middle part of the wood beam. The reference bar represents $10 \mathrm{~mm}$. water pressures (Rosner and Karlsson 2011). A total recovery from the pressure-induced dimensional change could not be observed because it is superimposed by increasing cell-wall shrinkage upon further drying (Hansmann et al. 2011). Cell wall shrinkage was initiated after the reversed radial dimensional change reached its peak, shortly before the slope of the MC curve reached its non-linear part (Figures $2 \mathrm{~b}$ and $3 \mathrm{~b}$ ). Similar radial dimensional changes caused by drying have been measured with several different methods (Rosner et al. 2009; Rosner et al. 2010; Hansmann et al. 2011).

\section{Moisture movement during drying assessed by $\mathrm{NI}$}

Lookup tables of neutron radiographies of the middle part of SW beams at 12 different MC stages beginning from the fully saturated state until 8-9\% MC are presented in Figures 2 and 3. At the onset of dehydration, more moisture evaporated near the transverse cut faces than in the middle part of the wood beams (data not shown). This was tested in a pretrial and demanded a much larger measuring window than $50 \mathrm{~mm} \times 50 \mathrm{~mm}$ which led to a lower resolution of the radiographies. However, specimens should have a specific minimum length $(100 \mathrm{~mm})$ to be able to observe dimensional changes caused by capillary forces, so that they do not dry too fast. To visualize water distribution within and between narrow annual rings in the region of interest (the central region of the SW beam), a smaller window was chosen leading to higher resolution radiographies.

Figures $2 \mathrm{a}$ and $3 \mathrm{a}$ indicate that removal of free water in the radial direction did not proceed continuously from the surface to the interior parts but was strongly dependent on wood anatomical characteristics. Removal of free water started in the
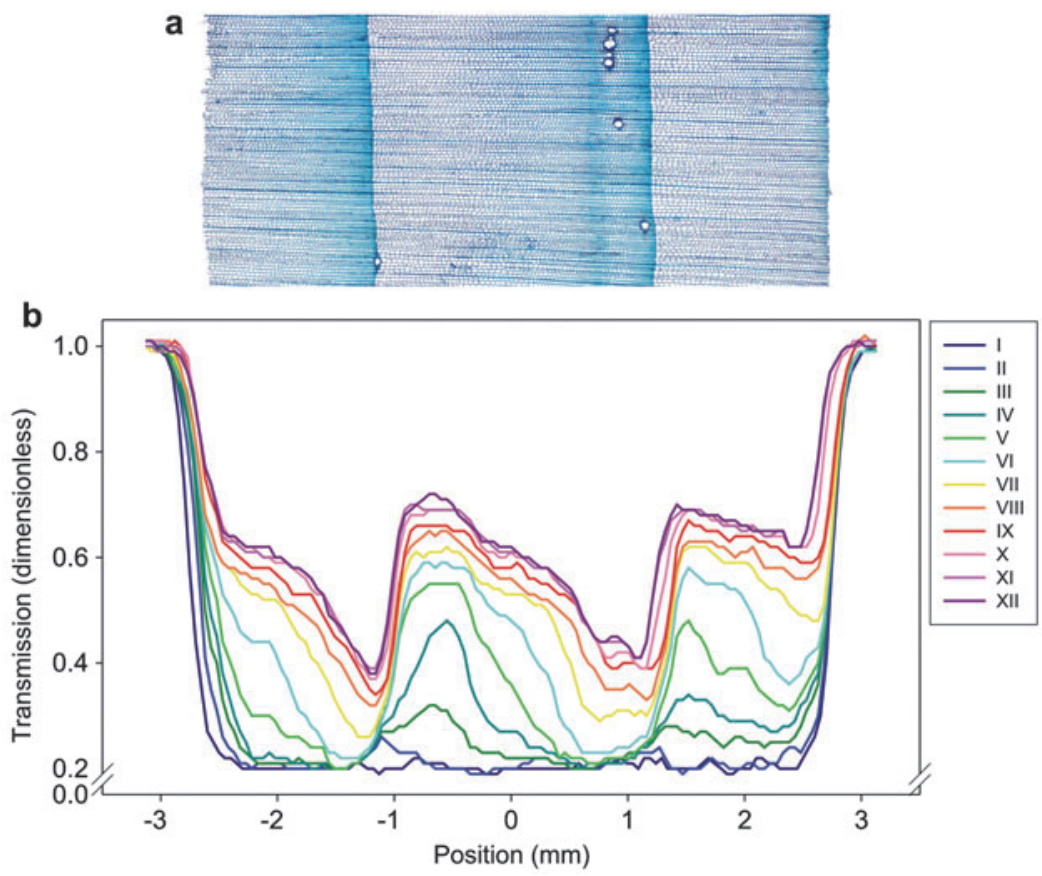

Figure 4 Transverse section (a) and transmission profiles of a sapwood beam with wide annual rings (Ekebo) at different moisture content steps; roman letters correspond to the moisture content steps shown in Figure $2 b(b)$. 
a
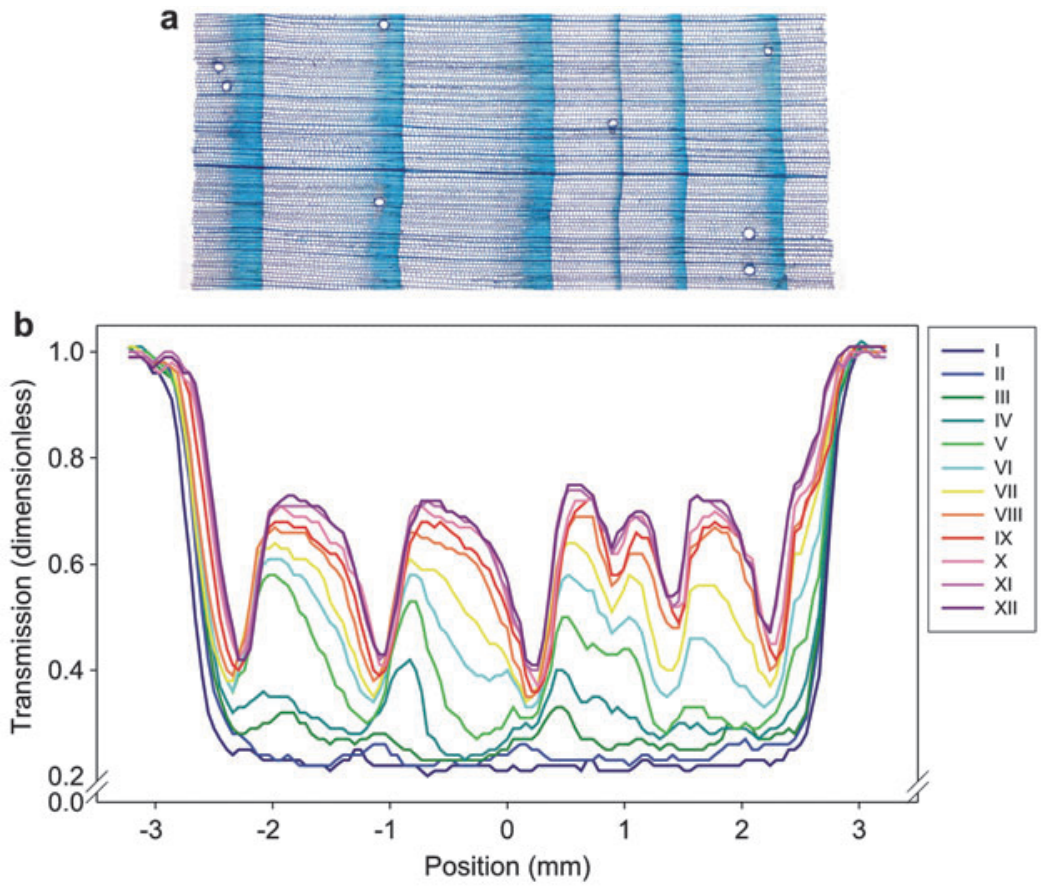

Figure 5 Transverse section (a) and transmission profiles of a sapwood beam with narrow annual rings (Prinzersdorf) at different moisture content steps; roman letters correspond to the moisture content steps shown in Figure $3 \mathrm{~b}$ (b).

outermost cell layers and in the high density latewood (LW) zones (Figures 4 and 5; stage II). Mild drought stress leads to pit aspiration in earlywood (EW) tracheids, whereas in LW it leads to to air seeding through pit membrane pores (Liese and Bauch 1967; Domec and Gartner 2002). It seems, therefore, that a small amount of free water is likely removed in LW first, because LW bordered pits are not prone to aspiration upon capillary action (Rosner et al. 2010) whereby water can easily move between the tracheids.

Air entry in EW occurs when the torus of the pit membrane is ripped out of its sealing position enough to allow air leakage (Hacke and Sperry 2001). At bulk MCs between $150 \%$ and $50 \%$, free water was merely been removed from the EW. This process started in the first EW cell rows, which have low density and are highly vulnerable hydraulically (Figures 2-5; stage III-IV). When MC approached fiber saturation, free water also evaporated from the high density LW regions (Figures 2-5; stage VII). Almost no changes in the transmission could be observed after most cells were below fiber saturation, i.e., when the slope of the MC became linear again (Figure 2b: stage X-XII, Figure 3b: stage XI-XII). Where cell wall shrinkage was still ongoing, the transmission plots were shifted slightly from outside to the center (Figures 4 and 5).

\section{Conclusions}

NI proved to be useful in visualizing that removal of free water in the middle part of the specimen did not proceed continuously from the surface to the central part. At MC $>50 \%$, water is merely removed from EW and thereafter from the main LW parts. It is therefore concluded that the reversibility of radial dimensional changes is not caused by continuous rewetting of the outer wood parts located beneath the wood surface, but caused by the capillary action of free water. This study is - to best of our knowledge - the first approach in visualizing moisture distribution during sapwood drying by NI. To be able to estimate the absolute amount of water transported in a specific compartment, oven-dry referencing of wood specimens was necessary. NMRI needs no dry referencing and should be applied in further research in this regard and also because it allows a clear separation between free and bound water. However, all up-to-date techniques have the problem that differential shrinkage processes during dehydration obscure moisture content analyses of specific compartments within a specimen. Thus, the application of speckle pattern tools to localize the same wood compartments in dry and wet conditions should be a topic of further studies.

\section{Acknowledgements}

This study was financed by the Austrian Science Fund (FWF): V146-B16.

\section{References}

Almeida, G., Gagné, S., Hernández, R.E. (2007) A NMR study of water distribution in hardwoods at several equilibrium moisture contents. Wood Sci. Technol. 41:293-307.

Araujo, C.D., Avramidis, S., MacKay, A.L. (1994) Behaviour of solid wood and bound water as a function of moisture content. A proton magnetic resonance study. Holzforschung 48:69-74. 
Blakemore, P., Langrish, T.A.G. (2008) Effect of pre-drying schedule ramping on collapse recovery and internal checking with Victorian ash eucalyps. Wood Sci. Technol. 42:473-492.

Booker, J.D. (1994a) Acoustic emission and surface checking in Eucalyptus regnans boards during drying. Holz Roh. Werkst. 52:383-388.

Booker, R.E. (1994b) Internal checking and collapse - which comes first? Proceedings of the 4th IUFRO Wood Drying Conference: Improving Wood Drying Technology. New Zealand, Forest Research Institute, Rotura: NZ, pp. 133-140.

Cox, J., McDonald, P.J., Gardiner, B.A. (2010) A study of water exchange in wood by means of 2D NMR relaxation correlation and exchange. Holzforschung 64:259-266.

Domec, J.-C., Gartner, B.L. (2002) How do water transport and water storage differ in coniferous earlywood and latewood? J. Exp. Bot. 53:2369-2379.

Dvinskikh, S.V., Henriksson, M., Berglund, L.A., Furó, I. (2011) A multilinear magnetic resonance imaging (MRI) study of wood with absorbed water: estimating bound water concentration and local wood density. Holzforschung 65:103-107.

Grabner, M., Cherubini, P., Rozenberg, P., Hannrup, B. (2006) Summer drought and low earlywood density induce intra-annual radial cracks in conifers. Scand J. For. Res. 21:151-157.

Hacke, U.G., Sperry, J.S. (2001) Functional and ecological xylem anatomy. Perspect. Plant Ecol. Evol. Syst. 4:97-115.

Hansmann, C., Konnerth, J., Rosner, S. (2011) Digital image analysis of radial shrinkage of fresh spruce (Picea abies L.) wood. Wood Mat. Sci. Eng. 6:2-6.

Hietz, P., Rosner, S., Sorz, J., Mayr, S. (2008) Comparison of methods to quantify loss of hydraulic conductivity in Norway spruce. Ann. For. Sci. 65:502-507.

Innes, T.C. (1995) Collapse and internal checking in the latewood of Eucalyptus regnans F. Muell. Wood Sci. Techn. 30:373-383.

Kawamoto, S., Williams, R.S. (2002) Acoustic emission and acousto-ultrasonic techniques for wood and wood-based composites - A review." Madison, WI: Gen Techn Rep FPL-GTR-134. U.S. Department of Agriculture, Forest Service, Forest Products Laboratory, pp. 1-16.

Lehmann, E., Vontobel, P., Scherrer, P., Niemz, P. (2001a) Application of neutron radiography as method in the analysis of wood. Holz Roh. Werkst. 59:463-471.

Lehmann, E.H., Vontobel, P., Wiezel, L. (2001b) Properties of the radiography facility NEUTRA at SINQ and its potential for use as European reference facility. Nondestruct. Test. Eval. 16:191-202.

Lehmann, E.H., Vontobel, P., Kardjilov, N. (2004) Hydrogen distribution measurements by neutrons. Appl. Radiation Isotopes 61:503-509.

Liese, W., Bauch, J. (1967) On the closure of bordered pits in conifers. Wood Sci. Technol. 1:1-13.

Mannes, D., Lehmann, E., Cherubini, P., Niemz, P. (2007) Neutron imaging versus standard X-ray densitometry as a method to measure tree-ring wood density. Trees 21:605-612.

Mannes, D., Josic, L., Lehmann, E., Niemz, P. (2009a) Neutron attenuation coefficients for non-invasive quantification of wood properties. Holzforschung 63:472-478.

Mannes, D., Sonderegger, W., Hering, S., Lehmann, E., Niemz, P. (2009b) Non-destructive determination and quantification of diffusion processes in wood by means of neutron imaging. Holzforschung 63:589-596.

Mayr, S., Rosner, S. (2011) Cavitation in dehydrating xylem of Picea abies: energy properties of ultrasonic emissions reflect tracheid dimensions. Tree Physiol. 31:59-68.
Moon, R.J., Wells, J., Kretschmann, D.E., Evans, J., Wiedenhoeft, A.J., Frihart, C.R. (2010). Influence of chemical treatments on moisture-induced dimensional change and elastic modulus of earlywood and latewood. Holzforschung 64:771-779.

Niemz, P., Lehmann, E., Vontobel, P., Haller, P., Hanschke, S. (2002) Investigations using neutron radiography for evaluation of moisture ingress into corner connections of wood. Holz Roh- Werkst. 60:118-126.

Offenthaler, I., Hietz, P., Richter H. (2001) Wood diameter indicates diurnal and long-term patterns of xylem water potential in Norway spruce. Trees 15:215-221.

Perämäki, M., Nikinmaa, E., Sevanto, S., Ilvesniemi, H., Siivola, E., Hari, P., Vesala, T. (2001) Tree stem diameter variations and transpiration in Scots pine: an analysis using a dynamic sap flow model. Tree Physiol. 25:889-897.

Putoczki, T.L., Nair, H., Butterfield, B., Jackson, S.L. (2007) Intraring checking in Pinus radiata D. Don: the occurrence of cell wall fracture, cell collapse, and lignin distribution. Trees 21:221-229.

Rosenkilde, A., Glover, P. (2002) High resolution measurement of the surface layer moisture content during drying of wood using a novel magnetic resonance imaging technique. Holzforschung 56:312-317.

Rosenkilde, A., Gorce, J.-P., Barry, A. (2004) Measurement of moisture content profiles during drying of Scots pine using magnetic resonance imaging. Holzforschung 58:138-142.

Rosner, S., Karlsson, B. (2011) Hydraulic efficiency compromises compression strength perpendicular to the grain in Norway spruce trunkwood. Trees 25:289-299.

Rosner, S., Karlsson, B., Konnerth, J., Hansmann, C. (2009) Shrinkage processes in standard-size Norway spruce wood specimens with different vulnerability to cavitation. Tree Physiol 29:1419-1431.

Rosner, S., Klein, A., Wimmer, R., Karlsson, B. (2006) Extraction of features from ultrasound acoustic emissions: a tool to assess the hydraulic vulnerability of Norway spruce trunkwood? New Phytol. 171:105-116.

Rosner, S., Konnerth, J., Plank, B., Salaberger, D., Hansmann, C. (2010) Radial shrinkage and ultrasound acoustic emissions of fresh versus pre-dried Norway spruce wood. Trees 24:931-940.

Salin, J.G. (2007). External heat and mass transfer. In: Fundamentals of wood drying. Ed. Perré, P. A.R.BO.LOR, Nancy. pp. 175-201.

Simpson, W., TenWolde, A. (1999) Physical properties and moisture relations of wood. In: Wood handbook-wood as an engineering material. Gen. Techn. Rep. FLP-GTR-113. U.S. Department of Agriculture, Forest Service, Forest Products Laboratory, Madison, WI. pp. 1-24.

Skaar, C. Wood-Water Relations. Springer-Verlag, Berlin, 1988.

Sonderegger, W., Hering, S., Mannes, D., Vontobel, P., Lehmann, E., Niemz, P. (2010) Quantitative determination of bound water diffusion in multilayer boards by means of neutron imaging. Eur. J. Wood Prod. 68:341-350.

Tarmian, A., Remond, R., Faezipour, M., Karimi, A., Perré, P. (2009) Reaction wood drying kinetics: tension wood in Fagus sylvatica and compression wood in Picea abies. Wood Sci. Techn. 43:113-130.

Tremblay, C., Cloutier, A., Fortin, Y. (2000) Experimental determination of the convective heat and mass transfer coefficients for wood drying. Wood Sci. Techn. 34:253-276.

Tyree, M.T., Zimmermann, M.H. Xylem structure and the ascent of sap. Springer, Berlin, 2002.

Received November 19, 2011. Accepted January 23, 2012. Previously published online February 16, 2012. 